\title{
Construction of STEAM Curriculum Model and Case Design in Kindergarten
}

\author{
Zhang Mengmeng1, Yang Xiantong², Wang Xinghua,"* \\ ${ }^{1}$ Faculty of Education, Beijing Normal University, Beiing, China \\ ${ }^{2}$ Elementary Education College, Capital Normal University, Beiing, China \\ ${ }^{3}$ Faculty of Education, Beijing Normal University, Beiing, China \\ *Corresponding author: xinghua.wang@bnu.edu.cn
}

Received May 14, 2019; Revised June 18, 2019; Accepted July 10, 2019

\begin{abstract}
Learning of science, technology, engineering, art and mathematics (STEAM) have been recognized as key levers in the progress toward high quality preschool education for all kids. STEAM activities can be an effective platform for providing rich learning experiences and cultivating problem-solving ability that are accessible to kids. Firstly, the characteristics of the STEAM curriculum design in kindergarten are analyzed. Then, this paper constructs the STEAM curriculum design model and explains how the procedure of model is implemented in preschool education. Finally, the case for providing rich learning experience and kids' problem-solving ability in the context of STEAM education is designed. The construction of the STEAM curriculum model in kindergarten is to promote the smooth development of STEAM education in China.
\end{abstract}

Keywords: STEAM education, curriculum model, case design, kindergarten

Cite This Article: Zhang Mengmeng, Yang Xiantong, and Wang Xinghua, "Construction of STEAM Curriculum Model and Case Design in Kindergarten.” American Journal of Educational Research, vol. 7, no. 8 (2019): 485-490. doi: 10.12691/education-7-7-8.

\section{Introduction}

STEM education is a national strategy proposed by the United States to improve national competitiveness and innovation ability [1]. STEAM (Science, Technology, Engineering, Arts, and Mathematics) education emerged as a new pedagogy during the Americans, in response to the need to increase student learning interest innovation ability and practice skills in STEAM fields [2].

As educators and researchers realize the importance of STEAM education, more and more countries are extending education from primary education to preschool education, such as America, Australia, South Korea, Singapore and so on [3]. Relevant studies have shown that STEAM education in the early education stage plays a positive role in improving student creativity, innovation, engagement, problem solving skills, and other cognitive benefits [4], and in terms of improving teamwork, communication, adaptability skills for future career and economic advancement [5]. Especially with the rapid development of science and technology such as the Internet and artificial intelligence, the process and prosperity of country needs to rely on innovative talents of science and technology. As children are important talents for the future progress and development of society, it's necessary to update early childhood curricula in order to keep up with this international trend and address the growing need for engineering programs in early childhood school [6].
Therefore, this integrative literature investigates how STEAM education in kindergarten is studied. At present, research in China focuses mainly on the necessity of STEAM education, "how to teach" and "what to teach". As a result, STEAM curriculum is "activity-oriented", causing children to rush through various activities and materials, and less to participate in deep thinking triggered by process phenomena. Especially in previous research on the problem of "how to teach" lack of systematic teaching and children's developmental perspective. Therefore, this paper designs a STEAM curriculum practice model to promote children's effective learning based on Guidance on Learning and Development for Children Aged 3 6 in China and Next Generation Standards for Science Education in US, hoping to provide reference for STEAM education practice in China's preschool education.

\section{Literature Review}

\subsection{STEAM Education in Kindergartens}

From a pedagogical point of view, Traditional lecture-style teaching and standardized evaluation cannot satisfy the experience of educators and children in STEAM activities [7]. This perspective ignores the process of children's exploration and creation, in which, the real-world problems and the meaningful applications are not reflected in the activities students are given [8]. If the themes of the activities are authentic and applicable to the real world, children's motivation and enthusiasm for participation will 
be significantly increased [9]. Thus, the activity design based on STEAM curriculum can not only conform to the children's cognitive needs but also improve their comprehensive practical skills. We argue for the education model of interdisciplinary exploration in kindergarten contexts [10].

\subsection{Literature Review of STEAM Curriculum Design}

Previous studies have found that many children do not get the rich preschool STEAM experiences that could influence their school readiness and ultimate school success [11]. The reason is that supports for STEAM activities are equally limited, educators spend little time in either curriculum design or activities [10]. However, the relative studies deem that integrating STEAM into their preschool curricula can be a lever to create effective learning environment that is accessible to all students in the classroom [10]. In order to improve the abilities of Science, Math and Dual Language for preschoolers in STEAM education, Kimberl (2018) design a SciMath-DLL model to provide educators and practitioners with rich content and pedagogical strategies that make STEAM activities accessible to all children. In addition, Massachusetts issued a Teaching Guide to propose that the design of STEAM curricula should follow the characteristics of children's thinking development. Moreover, the design of activities should reflect the disciplinary perspective and five sensory experiences to promote the acquisition of children's direct experience [12].

\section{Principles of STEAM Curriculum Design in Kindergarten}

The essence of STEAM education is to connect five subjects closely, develop children's STEAM literacy and flexibly solve practical problems through integrated teaching. STEAM education activities in kindergarten should follow the following principles:

\subsection{The Principle of Interdisciplinary Learning}

STEAM education emphasizes the principle of interdisciplinary learning, then single-domain courses that are not STEAM education. Interdisciplinary learning means that teachers in STEAM education no longer focus on a specific subject, but on a specific problem, emphasizing the use of science, technology, engineering, art or mathematics and other interrelated knowledge to solve real problems. The integration of interdisciplinary learning not only enables children to have a deeper understanding of the content of a single field, but improves children's ability to comprehensively apply multidisciplinary knowledge.

\subsection{The Principle of Contextualization}

The design and implementation of STEAM curricula should be based on real or similar social contexts. Children learn differently in different situations, so that meaningful learning can only happen if it is embedded in the context of the application of relevant knowledge. Therefore, teachers need to provide various real situations that conform to the psychological characteristics of children and are close to the reality of world, and constantly improve the level of children's problem-solving ability by exploring ways to solve problems in the real situation.

\subsection{The Principle of Interest}

In order to encourage children to get satisfaction by exploring the process of problem solving and stimulate their intrinsic learning motivation, the implementation of STEAM education activities must be interesting [13]. In addition, due to the limitation of children's age level, thinking development mainly focuses on concrete image thinking. So the design of the STEAM curricula for preschoolers should be consistent with the cognitive development stage and in the form of interest. For example, educators integrate elements, methods and frameworks of game into educational activities, so as to cultivate their interest in exploring activities, promote their scientific attitude and mastery of knowledge and skills, and lay a foundation for their hands-on practice and problem-solving ability [14].

\subsection{The Principle of Inquiry}

The key indicator to judge whether children are really involved in activities lies in whether they have conducted in-depth exploration, which aims to cultivate children's creative thinking and problem-solving ability. Children actively participate in STEAM education activities and rely on their own direct experience to explore and find answers. In particular, children can express their conclusions in a variety of ways, so as to improve their initial problem-solving ability, creative ability, communication ability and operational ability, and form positive emotional experience and attitude.

\subsection{Ill-defined Task and Well-defined Outcome}

The solution to a real problem is often accompanied by well-defined outcome and multiple ways to solve the problem. Therefore, in the implementation of STEAM education activities, teachers are required to throw out a specific problem and the goal to be achieved, but the way to solve the problem should not be overly restricted, leaving space for children to explore and find the answers [15].

\section{The Construction of STEAM Curricula Model for Kindergarten}

STEAM education is a typical sociocultural and constructivist model, which provides children with learning situations and enables them to actively build knowledge and acquire skills through exploration, discovery, cooperation and other channels [16]. Therefore, this paper attempts to propose STEAM curriculum model suitable for early childhood by referring to the basic mode of constructivism (as shown in Figure 1). This model with "project or problem" 
as the core foothold, surrounding the key links of project theme (problem solving process), the explicit learning environment (environment establishment), Learning activities (interest stimulation, group cooperation, brainstorming, hands-on exploration, interactive sharing), learning scaffold (peer coaching, teacher's guidance) and learning evaluation (improvement) to design activity. At the same time, educators pay attention the transfer and promotion of children's experience after the completion of activities.

\subsection{Identify the Project Theme}

Before carrying out exploratory activities, preschool educators need to determine the project theme in combination with teaching objectives, children's characteristics, teaching content and other aspects. Teaching objectives should meet the three-dimensional objectives of knowledge and skills, process and methods, attitude and emotions according to variety of students at the different stages. At the same time, the designed activities should conform to the characteristics of children's age. In terms of learning content, mathematics, engineering, technology, science and arts should be integrated to reflect the integration of interdisciplinary fields. Specifically, for the field of science, engineering and technology, the Next Generation Science Standards of the United States can be used for reference [17]. For mathematics and arts content in STEAM education, educators can refer to the Learning and Development Guide for Children Aged 3-6 Years to provide guidance for designing effective STEAM activities.

\subsection{Establish Environment}

The creation of environment includes providing physical environment and psychological environment for children.
Physical environment means that educators provide appropriate spaces and facilities for children's activities. Psychological environment means that educators provide children with a relaxed and free psychological atmosphere, including psychological warmth provided by teachers and peers. For example, teachers' positive attitude towards children, the harmonious learning community in peer groups, and the voluntary observance of orders and rules in the living environment, etc. It can be seen that positive environment atmosphere provides basic guarantee for children's active learning and exploration [18].

\subsection{Arouse Interest}

Educators attract children's attention and curiosity by asking or showing visual aids. On the basis of attracting children's interest, educators expand children's understanding of the theme of the project through relevant model display, picture display, video play and other ways. This is the premise of STEAM education to promote children's active inquiry.

\subsection{Group Cooperation Investigation}

The essence of STEAM education promote problem solving, while real problems are often complex and diverse, requiring learners to have a clear sense of purpose and cross-knowledge reserves in multiple fields, and to cooperate with each other to solve various problems in learning. Therefore, "cooperation" and "dialogue" should be reflected in the design of STEAM education in preschool education, that is, children complete learning tasks through group cooperation, which is helpful to enhance children's initiative in learning and cooperative consciousness.

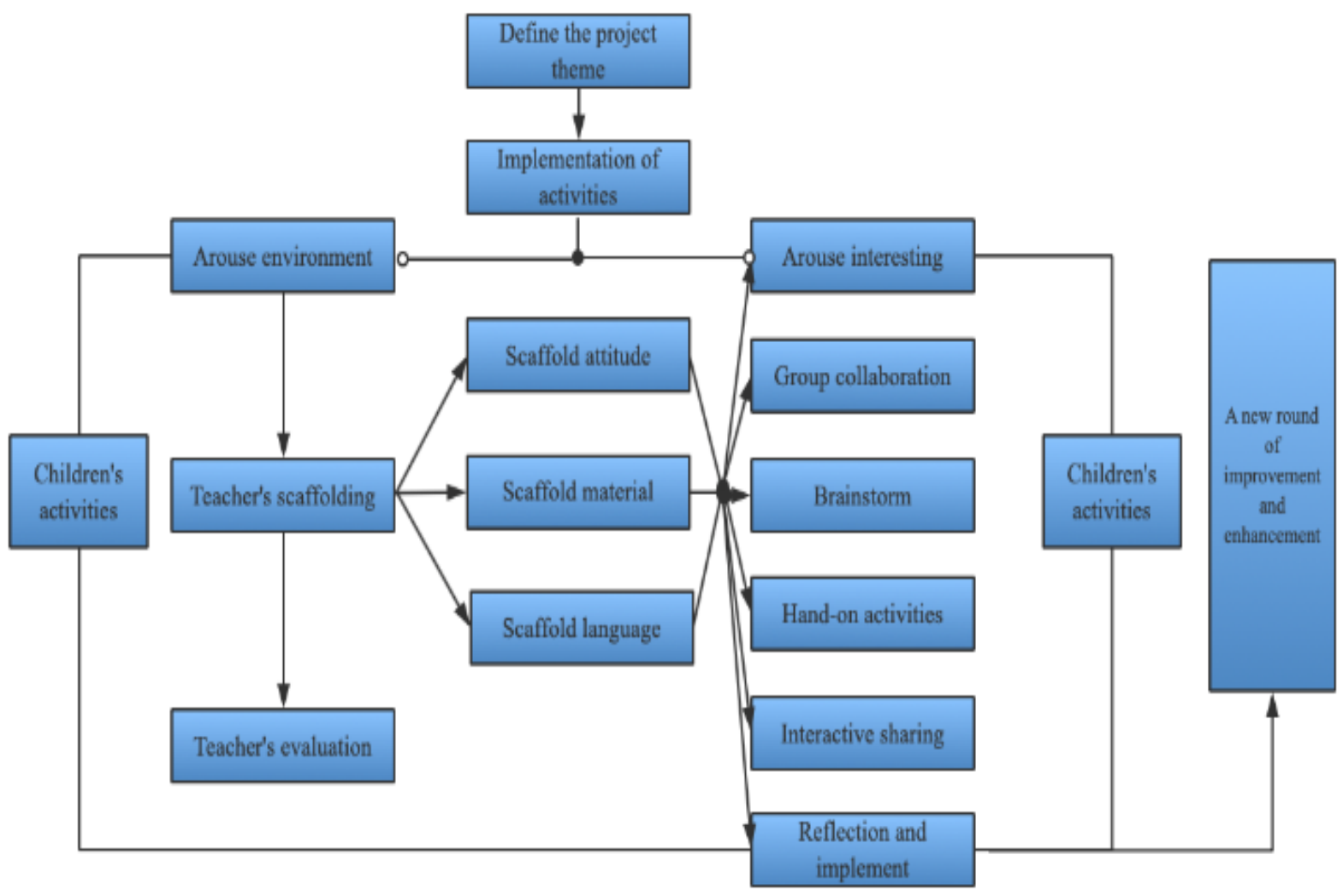

Figure 1. STEAM Curriculum Model in Kindergarten 


\subsection{Brainstorming}

When the children have identified the task problem, in the process of group cooperation, the educators can guide the children to brainstorm around the problem, but the teacher should not set limits on the children's ideas, but only ask them to express all the ideas they come up with. Although some ideas seem impossible, the expression process of children is a process of thinking and divergent thinking, which is the key step to improve children's understanding of problems and problem solving. Therefore, group members are required to have the courage to express their own opinions and focus on their views to further promote the solution of the problem.

The essence of STEAM education is to facilitate problem solving, while real problems are often complex and diverse, requiring learners to have a clear sense of purpose and knowledge reserves across multiple fields, and to cooperate with each other to solve various problems in learning.

\subsection{Hands-on Activities}

On the basis of group cooperation, children select materials according to the result of brainstorming, and try to operate according to the preset steps, and finally form the result. The process of children's hands-on exploration is actually a process of constantly trying to solve problems. In this process, children will encounter sudden problems. At this time, teachers should encourage children to take the initiative and try to solve problems through peer learning and cooperation. If necessary, teachers should provide scaffolding to guide children to form achievements.

\subsection{Interactive Sharing}

Interactive sharing is important step. On the one hand, by showing their work, the children share their design ideas with other groups, which exercises their language expression and communication skills. On the other hand, children expand their new ideas to solve problems by listening and learning the ideas, ideas and designs of other group works.

\subsection{Reflection and Improvement}

The educators clearly put forward the goals to be achieved, but they have no specific requirements for the process of solving problems for children. Especially after sharing with each group, children in each group can realize the existing problems through practice and peer experience to improve their own activity plan. On the other hand, educators observe and capture valuable feedback information from children to further improve the activity plan, so as to optimize the theme of this STEAM activity.

\section{The Curriculum Design}

STEAM education is a comprehensive, research-based way to solve real problems in real world. Before launching
STEAM education activities, we should clarify the objectives of the activities, but not stick to the task itself. In the process of activities, children should show the learning quality of initiative, earnest attention, not afraid of difficulties, dare to explore and try, willing to imagine and create. After the activity, educators could give appropriate intervention and guidance according to the change of activity conditions, and deepen understanding of knowledge, which is an ideal STEAM course.

\subsection{Project Name}

How to build a bridge? The reasons for choosing this theme are as follows: firstly, bridges can be seen everywhere in daily life, and almost all children have their own experience of crossing bridges. Second, it is difficult to build a solid bridge, but it can be done under the scaffold of teachers, which is in the development zone of children. Third, the process of building the bridge integrates knowledge of physics, mathematics, engineering, technology and art, which is the application of STEAM interdisciplinary educational philosophy.

\subsection{Materials}

Educators should provide materials to children, such as building blocks, plastic stick, ice cream stick, mineral water bottle, tape, glue, pigment, pigment pen, foam paper, etc.

\subsection{Objective}

\subsubsection{Science}

Children need to explore what kind of bridge structure will be more stable? How to decrease the weight of the bridge itself? What are the textures of the different materials used to make the bridge?

\subsubsection{Technology}

How to reduce the impact of sand and rain on the bridge in stormy weather? What are the structural components of a bridge?

\subsubsection{Engineering}

Children can design the ideal bridge structure through the form of painting to explore which materials will make the bridge stronger?

\subsubsection{Art}

The bridge designed by children is beautiful with appropriate color collocation, which up to the requirements of aesthetic education.

\subsubsection{Mathematics}

Children can calculate how many pieces of material are used, compare the role of different sizes of blocks in building bridges, and identify different shapes of materials. (ellipse, square, circle, sphere, cylinder, etc.) 
Table 1. Teaching Active Flow

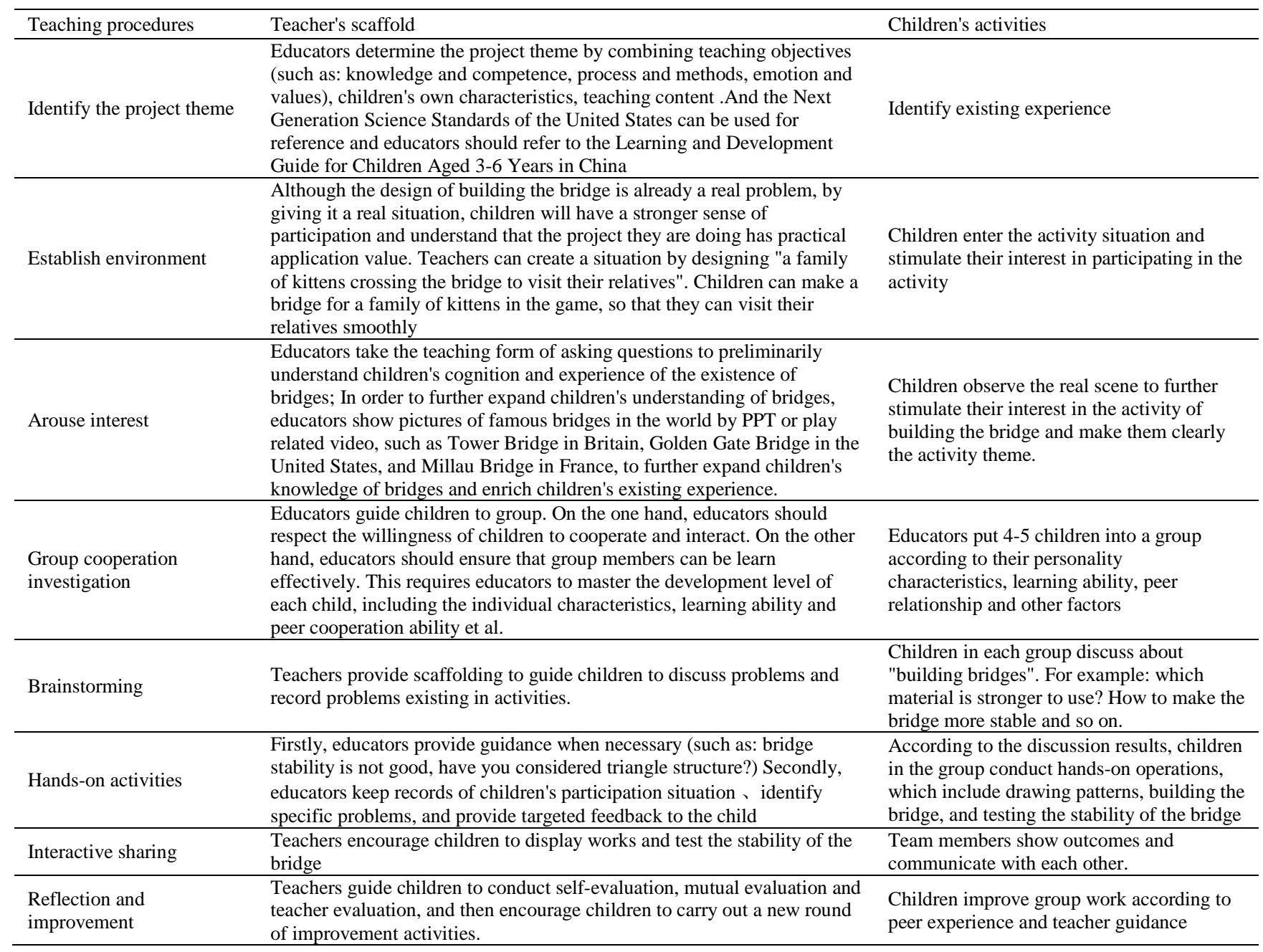

\section{Conclusion}

This article has been clearly clarify the principles for the implementation of STEAM activity in the kindergarten, and around the theme "project" as the core design the implementation model of STEAM curriculum, and through the activities of the specific case to elaborate the process of its activities. Its purpose is to help novice teachers quickly master the basic process of implementing STEAM curricula, so as to improve teachers' ability to organize and design STEAM activities. On the other hand, the purpose of implement provide children with multiple ways to be creative and cooperation within the context of real-world experiences. The form of interdisciplinary integration can effectively cultivate children's approaches to learning which include curiosity, interest, initiative, persistence, attentiveness and creativity. Furthermore, this will promote children learn and construct knowledge. STEAM should be promoted and in the early childhood setting for all children.

\section{Acknowledgements}

This work was support by Kindergarten Science Literacy and Kindergarten-based Curriculum Research Project (project number: SKHX2019015) .

\section{References}

[1] Hanaa, O., Khadri, A, Strategic Future Directions for Developing STEM Education in Higher Education in Egypt as a Driver of Innovation Economy. Journal of Education and Practice, 7(8): 127-145. Jan.2016.

[2] Elaine, P., Jen K.B, STEAM in practice and research: An integrative literature review. Thinking Skills and Creativity, (31):31-43. 2019.

[3] Lee, M.N., Chang, W, A Developing a STEAM-Based Instructional Design Model Using Storytelling for Early Childhood Education. Teacher Education Research, 58(1): 99116. Mar.2019.

[4] Root-Bernstein, R, Arts and crafts as adjuncts to STEM education to foster creativity in gifted and talented students. Asia Pacific Education Review, 16(2), 203-212. Mar. 2015.

[5] Kalogiannakis, M., Nirgianaki, G. M., Papadakis, S. Teaching Magnetism to Preschool Children: The Effectiveness of Picture Story Reading. Early Childhood Education Journal, 46(5): 535-546.2018.

[6] Bers, M.U., Ettinger, A.B, Programming Robots in Kindergarten to Express Identity: An Ethnographic Analysis. Industrial Engineering Concepts Methodologies Tools \& Applications.

168-184. 2012

[7] Sullivan, A., Bers, M.U, Robotics in the early childhood classroom: learning outcomes from an 8-week robotics curriculum in pre-kindergarten through second grade. International Journal of Technology and Design Education, 26(1):3-20. Feb. 2016.

[8] Kalliopi, K., Michail, K, Introducing fundamental objectoriented programming concepts in preschool education within 
the context of physical science courses. Education and Information Technologies. 23(6): 2673-2698. Nov. 2018.

[9] Guyotte, K.W., Ochacka, N.W, Costantino. Collaborative Creativity in STEAM: Narratives of Art Education Students' Experiences in Transdisciplinary Spaces. International Journal of Education \& the Arts, 16 (15):1-38.Oct.2015.

[10] Kimberly, B., Alissa, L., Irena, N, Integrating stem into preschool education; designing a professional development model in diverse settings. Early Childhood Education Journal, 47 (1):15-28.Jan. 2019.

[11] Tu, T, Preschool science environment: what is available in a preschool classroom? Early Childhood Education Journal, 33(4):245-251. Feb. 2006.

[12] Hu H.B, The Indicator Framework and Cultivation Strategies of Core Competencies of Science for Preschool Children in Pennsylvania and Its Inspiration, 33 (4), 90-96.2017. Studies in Foreign Education, 46 (1):51-64.Jan.2019.

[13] Bai W.W., Fang H.G., Huang X, Curriculum design research based on STAD type cooperative learning from the perspective of STEAM - a case study of game mathematics curriculum in primary schools. Modern Education Science, (10): 108-114. Oct.2017.

[14] Quigley C.F., Herro D., Jamil F.M, Developing a Conceptual Model of STEAM Teaching Practices. School Science and Mathematics, 117(1-2):1-12. Feb.2017.

[15] Chen D.Q, The Strategies of Early STEM Education Point to the Children's Learning Quality Development. Preschool Education research, (8):64-66.Aug.2018.

[16] Lindeman, K.W., Berkley, M.T., Jabot, M, The role of stem (or steam) in the early childhood setting. Advances in Early Education \& Day Care, 95-114. Aug.2014.

[17] Pruitt S.L, The next Generation Science Standards: Where are we now and what have we learned? Science Teacher, 38(9): 17.2015.

[18] Zhang M., Wang W., Yuan L, Activity design research of STEAM education in kindergarten. Modern Distance Education, (4):78-82.Apr.2018.

(C) The Author(s) 2019. This article is an open access article distributed under the terms and conditions of the Creative Commons Attribution (CC BY) license (http://creativecommons.org/licenses/by/4.0/). 